\title{
Attending to others: how digital technologies direct young people's nightlife
}

\author{
Jasmine Truong \\ Department of Geography, University of Zurich, Zurich, 8000, Switzerland \\ Correspondence: Jasmine Truong (jasmine.truong@geo.uzh.ch)
}

Received: 18 January 2018 - Revised: 8 May 2018 - Accepted: 9 May 2018 - Published: 31 May 2018

\begin{abstract}
It is a growing phenomenon that young people use mobile information and communication technologies during their nightlife. This article offers an empirical examination of how young people's nightlife is shaped by engagement with the mobile phone application WhatsApp. Drawing on Sara Ahmed's phenomenological concept of orientation, I examine how WhatsApp extends young people's nightlife and how young people become orientated therein. On the one hand, I show that nightlife acquires new boundaries and fixities that encourage young people to direct their attention towards missing social relations and absent nightlife places. On the other hand, I find that young people create new perceptions of how to inhabit and spend leisure time and space. I argue that digital technologies reorientate young people, which I suggest offers novel means of addressing young people's contemporary nightlife practices, places, spaces, and social relations.
\end{abstract}

\section{Introduction}

In recent discussions of the "digital turn" in human geography (Ash et al., 2016), one issue of concern has been how digital technologies shape practices and social relations in everyday life. In particular, scholars have shed light on how different people and communities use the information and communication technologies (ICTs) ${ }^{1}$ that shape how we relate to one another. With regard to young people, it has been shown, for example, how ICTs offer new geographies of leisure (Crowe and Bradford, 2006; Ruckenstein, 2013), enable ways of negotiating autonomy and independence from adult surveillance (Valentine et al., 2000; Thompson and Cupples, 2008), and facilitate intimate and sexual relations

\footnotetext{
${ }^{1}$ When referring to new digital technologies, human geographers apply various terms. While in recent discussions the notions of "digital (communication) technologies" (e.g. Adams, 2017; Rose, 2016b) and "digital media" (e.g. Longhurst, 2016a) are used, ICT is an older term that is nonetheless still used in discussions (Valentine et al., 2002; Zook et al., 2004; Valentine and Skelton, 2008; Longhurst, 2013; Kinsley, 2014). I use ICTs as an umbrella term that includes any communication and information through technology. This involves older media such as radio and television and more recent mobile technologies such as instant messaging, blogs, and video games.
}

(Downing, 2013; Bond, 2014). What this body of research helps us to understand is that online spaces are not separate or disconnected from the "real" world.

In recent public discussions in Switzerland, one controversial issue has been how ICTs affect young people's alcohol use. For example, one headline claims that "social media prevents young people from drinking" 2 while another asserts the opposite: "Facebook increases the desire to drink"3. In both perspectives, it is assumed that ICTs have an affect on young people's drinking, though in different ways. Alcohol research has recently advanced the idea that ICTs may create harmful "intoxigenic digital spaces" for young people (Griffiths and Casswell, 2010:525). The dissemination of alcohol-related photographs through ICTs extends peer drinking spaces beyond places such as bars, clubs, and urban public spaces. An emerging scholarship contends that young people are regularly exposed to and engage with proalcohol discourses online that may normalise their risky alcohol consumption (Brown and Gregg, 2012; Winpenny et al., 2014; Lyons et al., 2017). While these discussions have

\footnotetext{
"Soziale Medien hindern Jugendliche am Trinken" in 20 Minuten, 5 September 2016.

3“Facebook steigert Lust auf Alkohol", 20 Minuten online, 12 February 2015.
} 
foregrounded ICTs as new drinking "site(s) of representation and transference of symbolic meaning" (Griffiths and Casswell, 2010:526), there is little understanding of how these sites constitute young people's lived nightlife practices and experiences. Certainly, research has long shown that peer networks and friendship groups are central to youth drinking culture (Douglas, 1987; Overbeek et al., 2011; Fujimoto and Valente, 2012; MacLean, 2016). However, little research has addressed how digitally activated friendship connections and thus peer spaces through ICTs provide new territories for spatial practices of friendship. These, as argued by Bunnell et al. (2012), offer a unique window to explore wider processes of social ordering and transformation. Therefore, this study asks how the mobile phone application WhatsApp ${ }^{4}$ constitutes young people's nightlife spaces and how young people become orientated therein. Meanwhile, I work to address more closely the entanglement between young people's online and offline spaces that are active constituents of young people's "everynight" (Wilkinson, 2017:744). ${ }^{5}$

One decade ago, Jayne et al. (2008) made the point that the relationships between people, practices, spaces, and places are often under-theorised by those seeking to understand young people's nightlife and drinking practices. Since then, some work has been done towards filling that gap, for example through the approaches of actor-network theory (Duff, 2012), relational space (Demant and Landolt, 2014), and atmosphere (Wilkinson, 2017). However, the understanding of how online and offline practices, spaces, and places are intertwined in young people's nightlife is still in its infancy. In order to tease out this intertwining, I draw on Ahmed's (2006) idea of orientation. It allows critical engagement with how young people follow new practices and orientations through their attention towards WhatsApp chats. These extended nightlife spaces enable young people to link to single friends and friendship groups, send text messages, and share images, videos, audio messages, and user locations while out at night. Within seconds and a few taps on the screen, data files can be received, copied, modified, and shared more widely. In other words, WhatsApp constitutes young people's nightlife practices and experiences through establishing new lines of directions; that is, WhatsApp creates new boundaries and fixities of nightlife spaces that shape what appears "in front" of them, or in their view. This spatial perception encourages

\footnotetext{
${ }^{4}$ In January 2017 WhatsApp was worldwide the most popular mobile messaging application (https://www.statista.com, last access: 15 January 2018). When I did my fieldwork in 2014-2015, WhatsApp was the most popular application in Switzerland, both overall and among young people (Y\&R Group Switzerland, 2015). WhatsApp was launched in 2009. WhatsApp enables users to share text, images, audio, and video messages. In February 2014, Facebook acquired WhatsApp.

${ }^{5}$ Wilkinson's $(2016,2017)$ use of the term "everynight" refers to Malbon's (1998) notion of the "every-night life" in reference to young people's consumptions, identities, and spatial practices in nightclubs.
}

young people to direct their attention towards missing social relations and absent nightlife places while being out. Hence, I argue that ICTs reorientate young people in how they inhabit space and spend leisure time.

I show that an understanding of how and why young people are orientated to WhatsApp chats is important to address the significance of the stretched everynight spaces beyond physical spaces, which might include what Griffiths and Casswell (2010:525) call "intoxigenic digital spaces". Using Ahmed's (2006) phenomenological approach of orientation also resonates with Rose's (2016a:4) recent publication; this urges researchers not to focus so completely on the agency of the digital "that we neglect the networks of humans within which digital technologies are embedded, and the thoughts, feelings, processes and practices which are then mediated by such technologies".

I next introduce Ahmed's ideas on orientation. Before delving into empirical findings gathered from in-depth interviews with 20 young people, I detail the methodological process of this article, which has evolved from a larger research project in Switzerland on young people's going out and drinking practices.

\section{Becoming orientated}

Bringing Ahmed's work to bear on young people's digitally stretched nightlife offers the possibility to rethink social relations, cultural practices, and spaces bound up with drinking. In Ahmed's (2006) Queer Phenomenology, spaces and their relations to people and things become a question of orientation. That is, spaces and the way we relate to one another acquire new shapes depending on which way we turn. Directions taken not only allow things and people to be perceived but also enable us to take a position and a perception in relation to things and people.

Ahmed understands orientation as relational. She argues that we inhabit space "through tending towards objects" (Ahmed, 2006:2). Drawing on MerleauPonty's (2005) phenomenology and its element of relationality, Ahmed (2006:5) comprehends subjects' positions as "starting points". It is from there that we reach out towards the world. From there, orientations unfold, and there are specific "lines that direct us" (Ahmed, 2006:12). This relational understanding of orientations towards or away from particular objects helps to study how nightlife spaces adopt new shapes when young people tend towards their mobile phones as gateways to WhatsApp chats. In other words, orientation reveals how young people relate to and follow new lines of directions when orientated towards WhatsApp, while other things may become excluded from their perception when out of view.

Ahmed's (2006) orientation also involves a spatial dimension. She connects orientation closely with perception; that is, individuals and communities orientate towards objects 
that are reachable and perceivable. Ahmed understands perception to be twofold: you can perceive an object depending on your position and orientation. You can also have a specific perception of an object; that is, you may like it, admire it, or hate it. These two aspects of perception give you both a relation towards the object and a specific orientation towards it. In Switzerland, $99 \%$ of young people own a mobile phone, and the most popular mobile application is WhatsApp, followed by other communication technologies (Willemse et al., 2016). The omnipresence of ICTs maintains closeness to digital spaces and fosters reachability through and perception of WhatsApp. Having said this, the focus on who, what, and in which orientation young people direct their energy and attention towards WhatsApp chats helps to address more closely how young people's online and offline nightlife spaces are entangled.

As a queer thinker, Ahmed (2006) suggests that orientations are performative. Orientations are shaped through a repetitive process of turning towards or away from something over time. These orientations we follow might also function as alignments. In Ahmed's (2006:15) terms, "We are in line when we face the direction that is already faced by others. Being in line allows bodies to extend into spaces that, as it were, have already taken their shape". Apprehending orientations as performative also allows engagement with moments of disorientation. In these moments of "loss" (Ahmed, 2006:158), in which usual lines of directions become blurred or unfixed, worlds can become disorientating, or queer. Longhurst (2016b:117) contends that "currently we may be in a space of in-betweenness, a queer moment in which people are reasonably familiar with technology but not overly so". The performativity of orientation towards digital spaces today, then, may have a potential to destabilise and reconfigure normative ways of being and offer new directions within young people's everyday and everynight life. These moments of disorientation are vital to reground and reorientate to social relations, cultural practices, and spaces.

\section{Methodology}

Data presented here draw from a wider project titled Youth@Night, which explored urban nightlife practices, mobility, and the social context of young people, aged 1625 years, in Switzerland. The Youth@Night project involved an online questionnaire ( $n=367)$, in situ surveys that collected visual and sensor data ${ }^{6}$ through a mobile phone application downloaded onto participants' personal mobile phones $(n=168)$, and semi-structured interviews with a selected sample $(n=40)$.

While the entire interview sample comprises 40 interviewees from both the French-speaking part $(n=20)$ and the German-speaking part $(n=20)$ of Switzerland, in this arti-

\footnotetext{
${ }^{6}$ GPS (Global Positioning System), GSM (Global System for Mobile Communication), Wi-Fi, acceleration, and Bluetooth.
}

cle I draw on interviews with 20 young people who regularly spend their nights out in Zurich, the Swiss city with the widest range of nightlife opportunities. The interviewees were sampled on the basis of the preceding survey's results to include a balance in terms of gender, a deliberate spread across the age and educational background spectra, a diversity in drinking patterns, and a range in the use of ICTs during nights out. Most of the participants were still in some kind of education. While 10 of the participants were in vocational training, 9 attended or had just started higher education. One of the participants was already in regular employment.

The interviews involved participants' narratives about their "normal" nights out, their use of alcohol and other substances, their social relations and practices in both physical and digital spaces, their relations to their mobile phones in the everynight, and their reflections about using their personal mobile phones as research instruments to produce data on their nightlife places and practices. While in our project, the research participants were asked to use their mobile phones at specific moments of their evenings with specific instructions. This generated fruitful discussions and reflections in the interviews. All interview partners were stimulated to explain their habitual use of their mobile phones while free from both study instructions and the "absent-yet-present researcher" (Fassetta, 2016:702; see also Langevang, 2007). Thus, "disorientating" (Ahmed, 2006) young people in their nightlife activities both raised their consciousness and empowered the research participants to talk about their practices with digital technologies in their nightlives.

I conducted the interviews between November 2014 and March 2015. They took place at the participants' choice of site in coffee shops, restaurants, at participants' homes, and at university and lasted between 1.5 and $2 \mathrm{~h}$. The completely transcribed tape-recorded interviews were analysed through iterative rounds of coding using MAXQDA qualitative software. Pseudonyms are used in the following when referring to participants.

\section{Orientating towards participation and inclusion}

Going out at the weekend is a very common practice for all the participants in this study. What they are mostly looking for is to benefit from what nightlife offers, to hang out with friends, and to have fun. The omnipresence of connecting ICTs produce new boundaries of spaces that constitute what nightlife can offer, how young people participate in nightlife, who they attend to, and who they include in their night out activities. Jamie usually goes out twice a weekend. To the 16-year-old, going out primarily means being with friends. On a normal weekend evening, seeing them is "self-evident". When I interviewed Jamie, the teenager had been grounded on weekend evenings after breaching rules set by her parents. Not being allowed to go out, however, does not necessarily 
mean that Jamie misses out on all nightlife activities. With WhatsApp, Jamie is able to get in touch with the friends who are out:

Most of the time, when I have to stay at home and my friends are out, I'm glad when I'm in contact a bit [through WhatsApp] ... Then, I have the feeling that they think of me a bit. And they also miss me a bit, so to speak [laughs]. It's a bit like I experience a part of it. To me, it is not like I have no clue, I wasn't there, when they talk about the evening later on. So, at least [through WhatsApp] I experience a fraction [of nightlife], yes. Also, when they call me or the like, I feel as if I'm part of it [the experience], even though I'm not there. (Jamie, 16 years)

Within the WhatsApp group chat and through text messages, photographs, and video clips, Jamie engages in and experiences parts of nightlife. Even while grounded, nightlife appears in Jamie's "perceptual 'thereness" (Ahmed, 2006:25) and enables the teenager to be orientated towards participation in a weekend's evening. This orientation towards participation is not only meaningful for the immediate pleasure, but also for later, when Jamie's friends relive the evening. Then "it is not like I have no clue, I wasn't there". As scholars have shown, collectively remembering and reexperiencing nights out through storytelling (Tutenges and Sandberg, 2013), video records on mobile phones (Griffin et al. 2009), and posts on online social networks (Brown and Gregg, 2012) are valued social activities among young people. Therefore, WhatsApp groups provide new lines of participation and new territories for lived group experience. Being able to comment on the happenings, no matter how remote a group member is physically, also means that one has a role to play in recollecting nightlife happenings later on, whether online or offline.

Orientation towards participation by the absentee also involves orientation towards involvement by the people being out. Jules maintains a WhatsApp group chat with "the best friends" who normally spend the weekend evenings together. When one of them misses out on the common weekend evening, they include the absent person.

If from the [best friends'] group chat, there are just three of us going out, while the others are not able to join, then we take a video for the [absent] others. You send it to them [within the group chat] to say "see what we are doing". This is not to say, ha ha, you are not here, but to let the others experience it as well, so to speak. (Jules, 17 years)

Research has shown that young people's nightlife is central in building and maintaining friendships through sharing experiences and caring for one another (Johnson, 2011; Niland et al., 2013; Tutenges, 2013; MacLean, 2016). Jules uses WhatsApp to show and involve the absentees in the lived experiences. At the same time, WhatsApp supports young people in expressing bonding and solidarity by messages such as "would have been great, you should have come" (Michele, 19 years), "I think of you and I care about you" (Lou, 19 years), or "come next time" (Vivien, 20 years). Writing a WhatsApp message makes the sender pay attention to the absentee; it is "like [giving] a present" (Reese, 18 years). WhatsApp creates new lines to involve missing friends.

Being orientated towards participation and involvement through WhatsApp opens up possibilities to orientate towards and get in touch with absent friends: with their fingers, young people scroll down text messages, tap on video clips, zoom in on photographs of friends, and scale back. Mediating technology enables young people to move into each other's perception and thus makes them conscious of themselves. Thompson and Cupples (2008:96) note that "one's friends and their contact details are ever present symbolically in the mobile phone". Being potentially reachable and perceivable also encourages turning towards these ties.

The orientation towards involvement sometimes also moves beyond the circle of friends. ICTs also allow parents to enter young people's perceptions during nightlife. Lou's mother, for example, usually contacts the 19-year-old during a weekend's night out. Anticipating her attention, Lou becomes directed towards the mobile phone.

I always have to pay attention to my phone; otherwise she is worried about me. (Lou, 19 years)

Thompson and Cupples (2008:100) argue that young people use texting to interact with one another as a "private, and often unseen and unheard practice" that escapes adult surveillance (see also Furlong, 2013:150). Clearly, this applies to peer-to-peer communication within online spaces. However, the same channel of communication also allows adults to take a perceptual position in relation their children. Lou's mother's potential reaching out towards her child shapes Lou's orientation towards the parent in the course of the night out. In other words, being reachable permits parents to see and hear, which facilitates parental care and control beyond physical proximity (see also Longhurst, 2013). To return to Ahmed's (2006) twofold understanding of perception a specific orientation not only makes specific things and people to appear in our point of view but also enables us to situate ourselves in relations to things and people. Thus, the possibility that young people's wider network may be perceptually there through ICTs reorientate young people in two ways. WhatsApp enables them to direct their energy and attention towards absent friends and caring parents; the absentees can become perceptible. This in turn creates new ways of relating to physically absent others and thus new lines of participation and involvement in young people's nightlife spaces. The next section further elaborates on how young people orientate themselves and apprehend the urban night spaces when WhatsApp directs them to physically absent nightlife venues. 


\section{Orientating towards comparison, competition, and optimisation}

Sending and receiving visual images such as photographs and videos can create proximity, bonding, and solidarity in young people's nightlife experiences. However, exchanging and learning about what others are doing somewhere else can also enhance comparison and competition. Fran talks about being orientated towards friends and their drinking narratives at another nightclub.

You send a photo with the drink, for instance, when you are toasting. Afterwards, your girlfriends or another circle of friends sends one back. And then, it intensifies and increases mutually with alcohol drinking practices. (Fran, 20 years)

There has been increasing attention paid in the literature to social networking sites such as Facebook as new territories for young people to present and spread hedonistic drinking that may encourage harmful alcohol use (Brown and Gregg, 2012; Brunelle and Hopley, 2017; Lyons et al., 2017). However, due to a broad and diverse audience from different contexts on public social networking sites, self-presentations of drinking integrate a "balanced self-display" (Niland et al., 2014:886) that involves young people's judgments and negotiations of their intoxicated portrayals. In contrast, WhatsApp group chats enable images to be directed to specific and closed peer groups in real time, which engenders new lines of comparison and positioning within stretched peer environments.

However, orientations towards comparison and competition are not limited to drinking narratives. They also involve competing over who is more often at the cool place in town through sending messages to absent friends such as "haha, I am now in the X bar" (Lou, 19 years) or boasting about being at a concert of popular artists by sending a video recording.

Elia: When I go to a concert and I know friends of mine like them (the artists) but cannot attend the concert, I like to send them a video. "Look, it was really cool”. It's actually really mean, but [laughs] -..

Interviewer: Is your intention to share or to communicate "haha" - I was there and you weren't?

Elia: I just want to share this with a person. I don't really want to make her jealous. But it is normal that one wants to show off a bit, in the sense of "I was there and you weren't".

Comparing and reproducing nightlife narratives has been shown to be highly valued and identity-forming among peers (Workman, 2001; Griffin et al., 2009; Tutenges and Sandberg, 2013). While much of the literature focuses on young people aspiring to "build a repertoire of personal drinking stories" (Tutenges and Sandberg, 2013:543), the competition over who gathers more and better experiences goes beyond drinking narratives. It also involves who is at the cool places, sees the popular music bands, or attends the better parties, as described by Dominique.

Dominique: There were two really good parties [taking place at the same time]. Some went to this party; others went to that party. Then [you get in contact through WhatsApp] it's about [laughs] "who is at the better party". That's quite fun.

Interviewer: Do you then exchange photos and other things?

Dominique: Yes, mainly photos and sometimes a short video clip. In videos, you see and hear what happens.

While at different places, Dominique's group of friends interact in real time and compete over who is having the better time. This involves demonstrating "what music is on" (Dominique, 21 years), filming the crowd to show "the many people and the good atmosphere" (Toni, 19 years), or taking a picture at a bar and with a beer to say "we are out and having fun" (Robin, 20 years).

Seeing what others are up to and being orientated towards others' nightlife through WhatsApp also means being faced with what could also be possible. Being aware of multiple options shapes how Les moves within the urban night space.

Interviewer: Are there any places or districts you avoid when you go out?

Les: Yes, district A, district B. You are just so far away [both districts are on the outskirts of Zurich]. I feel like I'm going out of Zurich if I go there.

Interviewer: You don't want to go out of Zurich?

Les: No, I don't. I move a lot when I'm out. If someone sends a message [through WhatsApp] "hey are you also coming to this or that place?" - and you are in district A [laughs] or B with the bicycle, that's very inconvenient.

Les' tendency to avoid districts on the outskirts of Zurich and to stay in close proximity to potential events involves orientation towards constantly deciding where to go next. In fact, always carrying a mobile phone means practically carrying latent nightlife options in one's pocket, which matters in how the 22-year-old inhabits nightlife spaces. Instead of staying in one place, orientation towards WhatsApp enables Les to accumulate information about various nightlife happenings, coordinate the nightlife itinerary, and move to what may be a better place. WhatsApp connections encourage an orientation towards optimisation.

To sum up, the mobile phone application WhatsApp allows people, things, and options to appear in the perceptual thereness of its users. This reorientates young people 
in two respects: carrying the WhatsApp connections encourages young people to orientate towards and follow these connections. This also leads young people to acquire a specific perception of night spaces. The emergent dynamics of comparison, competition, and optimisation through ICTs reflect degrees of an entrepreneurial orientation (Lovink, 2011; Flisfeder, 2015) towards the leisure time and spaces of young people.

So far, I have shown that the research participants' nightlife can acquire new boundaries and fixities through WhatsApp which reorientate young people through new lines that direct them. However, these lines of participation and inclusion, comparison, competition, and optimisation created through connecting technologies can also be disorientating in young people's nightlife. In the next section that follows, I examine the narrative of some of the participants who experienced moments of disorientation when engaging with WhatsApp.

\section{Moments of disorientation}

Ahmed (2006) understands orientation to be performative. A specific orientation is shaped through an iterative and collective process. The orientation one follows might also be the direction that is already faced by others. However, these lines of directions can also become fragile and disorientating. Moments of disorientation are dislodged from the usual dimension and can have the effect of losing perspective (Ahmed, 2006). Many young people keep their mobile phones within reach while out. For example, Lou's partner does not like going out. To spend some time together on a weekend evening, they both orientate towards WhatsApp. "It quite often happens that I look at it [the phone] again and again", the 19year-old says. WhatsApp enables Lou to direct attention to the absent partner while with other friends.

I think WhatsApp is convenient. The whole communication through the mobile phone is convenient. But the problem is that you really have to watch out not to lose sight of the essential, of what is happening at the moment. (Lou, 19 years)

The orientation towards involving the absentee can become off the line of "what is happening at the moment". In Lou's words, one has to watch out not to lose perspective of the "essential" line, by which the interviewee refers to physical togetherness with friends. As soon as the phone vibrates and its screen lights up, it is so easy "to slip away" (Lou, 19 years), which can be disorientating and annoying.

Sometimes you see the people tapping (on their phones) all evening long. That annoys me. Because I think, when you are out with people, why do you look at your phone all the time? That's what you do when you're home or by yourself. (Jamie, 16 years)
Young people have grown familiar to a wider horizon of social togetherness. The boundaries between the here and the there are increasingly blurred as they engage with WhatsApp messages from many different places. Technologies can change orientations and reorientate people, as discussed in the previous sections. However, as Ahmed (2006:59) says, "what we 'do do' affects what we 'can do"". That is, while certain orientations introduce and expand capacities in particular directions, this might restrict what we can do in others. Although both Jamie and Lou expand nightlife comfortably into mobile WhatsApp chats, they sometimes experience these moments as loss. Switching dimensions into "the virtual" can disturb or "queer" the usual sense of being social, which is to "personally talk to the people who are there rather than ... being on the phone and not talking to each other" (Taylor, 17 years).

Being orientated, "we might not even notice that we are orientated" (Ahmed, 2006:5). Through WhatsApp, Fran says, "somehow, you can share everything and you are a little involved everywhere". However, the 20-year-old does not always feel comfortable with that orientation and calls it into question:

I don't know if it's that good. You just don't really live the moment and the things you do. You're always thinking about the others, about what could be possible and what could be even better. (Fran, 20 years)

Textual, visual, and audio-based messages can engender the feeling of being haunted by what might be better. They make present something that is now absent that may unsettle or disorientate. "Moments of disorientation are vital", Ahmed (2006:157) says. They offer the opportunity to not simply reproduce the lines we follow but to wonder what it means to be orientated. The point is "what we do with such moments of disorientation" (Ahmed, 2006:158). While young people expand their nightlives into digital social spaces, at certain moments these expansions seem to compete with physical togetherness. Some scholars argue that mediating media and much of the content presented through digital screens creates a form of "hyper attention" (Hayles, 2007) and "distracted present" (Stiegler, 2010; Rushkoff, 2013) in which, instead of enjoying one activity, "we hop from choice to choice with no present at all. Our availability to experience flow or to seize the propitious moment is minimized" (Rushkoff, 2013:115). This distracted and disorientating presence, when young people lose track of the "real" nightlife, the returning to the physical present unveils to be the "right" orientation to reach for.

\section{Conclusion}

Focusing on young people's leisure and night-time unfolding across ICTs, this article has looked at how WhatsApp shapes 
young people's urban nightlife spaces and directs their practices and experiences. Our understanding of urban night-time activities is dominated by a strong emphasis on alcohol and drug use (Wilton and Moreno, 2012), including the nightliferelated online activities. A growing scholarship is concerned with the "intoxigenic digital spaces" (Griffiths and Casswell, 2010:525) produced through ICTs (Griffiths and Casswell, 2010; Brown and Gregg, 2012; Niland et al., 2014; Lyons et al., 2017); it draws on the "pathologizing of alcohol consumption" (Jayne et al., 2008:249) and predominant understandings of young people as vulnerable and in need of protection (Valentine, 1996; Aitken, 2001). Through the lens of Ahmed's phenomenological reading and reflections on orientation, I have found that young people orientate themselves in much broader ways towards ICTs. Mediating technologies not only allow people, practices, places, and spaces to appear in their nightlife but also enable young people to find their ways through nightlife by situating themselves in relation the things that emerge in their perceptual thereness.

My findings suggest that young people are directed in contemporary urban nightlife in some ways more than others. Through the omnipresence of mobile phones and proximity to numerous WhatsApp connections, I have shown that many young people are orientated to both a temporary participation in absent nightlife happenings and involvement with missing friends. Through WhatsApp, new ways of orientations extend physical boundaries to "feel an affiliation or affection with others, forging and re-forging their self- and group identities" (Malbon, 1998:266), an aspect that has been discussed as valued experiences of young people's nightlife (see also Tutenges, 2013). Nightlife spaces therefore acquire new boundaries and fixities (in the sense of Butler, 1993) and, as I have argued, reorientate young people, tending towards a broader horizon of friendship practices and wider windows of nightlife experiences. These new territories are not "passive backdrops" (Wilkinson, 2017:739) but actively shape how young people inhabit and experience nightlife.

Furthermore, using Ahmed's concept of orientation enabled a consideration of not only how ICTs direct young people within their lived nightlife spaces but also how they become orientated and apprehend these wider horizons of nightlife. Through WhatsApp, young people direct their energy and attention towards absent others, and they also relate in a specific way to these people and places. Grasping at participation and involvement through textual, visual, and audio messages advances a blurring of the here and the there which, I have shown, strengthens an orientation towards comparison, competition, and optimisation of nightlife. This burgeoning perception involves degrees of what Flisfeder (2015:555) terms "entrepreneurial ethics" unfolding across ICTs and, as this study shows, intermingles with young people's leisure time and space. This, I contend, illuminates the spatial and perceptual aspects of nightlife, which offer novel means of addressing nightlife, alcohol, drinking, and drunkenness in young people's online and offline spaces.

Finally, real-time images and sounds shared through WhatsApp create "synchronised spaces" (Longhurst, 2013:676) of lived experiences. I have shown that the orientation towards others can also become annoying, unsettling, and disorientating. It can create a "distracted present" (Rushkoff, 2013) in which young people's attention turns away from what they are currently doing or who they are currently with. The question of orientation is not only a question about how "we find our way" but also "how we come "to feel at home", (Ahmed, 2006:7). That is, the work of inhabiting space involves negotiation between the lines we follow and the condition of feeling comfortable. Whilst WhatsApp enables young people to extend into a wider nightlife space, it also distracts from living in the here and now, moments of communion, and moments of "losing yourself" (Malbon, 1998:274). The omnipresence of ICTs within young people's nightlife can encourage what Abbott-Chapman and Robertson (2009:247) call an "“always-on' imperative"; technologies reorientate young people, but these reorientations are at this moment in history sometimes still unfix and fragile. Geographers' discussions on the "digital turn" (Ash et al., 2016) have invoked fundamental questions of reorientation, rethinking, and reframing our being in the world. The moments of disorientation that I have discussed in these micro-geographies of young people's nightlife are vital to negotiating which directions we want to follow when ICTs co-constitute the spaces we inhabit.

Data availability. For data protection reasons transcriptions of interviews that formed part of the methodology are not publicly available.

Competing interests. The author declares that she has no conflict of interest.

Acknowledgements. This article is part of the research project "Youth@Night - A multi-disciplinary multi-method study of young people's going out and drinking behaviors" funded by the Swiss National Science Foundation under grant number 150181. I would like to thank the interviewees for their time and openness in sharing their nightlife stories. I am grateful for the stimulating and pleasant working environment within the Youth@ Night project and team. I thank Vera Bäriswyl for transcribing the interviews and Sara Landolt for her support and advice while this work was being written. Finally, I would also like to thank the anonymous reviewers for the constructive and helpful comments and Myriam HoussayHolzschuch for her work, support and encouragement along the way.

Edited by: Myriam Houssay-Holzschuch Reviewed by: two anonymous referees 


\section{References}

Adams, P. C.: Geographies of media and communication I: Metaphysics of encounter, Prog. Hum. Geog., 41, 365-374, https://doi.org/10.1177/0309132516628254, 2017.

Ahmed, S.: Queer Phenomenology: Orientations, Objects, Others, Duke University Press, Durham, NC, 2006.

Aitken, S. C.: The Geographies of Young People: The Morally Contested Spaces of Identity, Routledge, London, New York, 2001.

Ash, J., Kitchin, R., and Leszczynski, A.: Digital turn, digital geography? Prog. Hum. Geog., 42, 25-43, https://doi.org/10.1177/0309132516664800, 2016.

Bond, E.: Childhood, Mobile Technologies and Everyday Experiences, Changing Technologies $=$ Changing Childhoods?, Palgrave Macmillan, New York, 2014.

Brown, R. and Gregg, M.: The pedagogy of regret: Facebook, binge drinking and young women, Continuum, 26, 357-369, https://doi.org/10.1080/10304312.2012.665834, 2012.

Brunelle, C. and Hopley, A. A. B.: The role of drinking norms and social networking sites on alcohol consumption in university students, J. Subst. Use, 22, 1-7, https://doi.org/10.1080/14659891.2016.1271035, 2017.

Bunnell, T., Yea, S., Peake, L., Skelton, T., and Smith, M.: Geographies of friendships, Prog. Hum. Geog., 36, 490-507, https://doi.org/10.1177/0309132511426606, 2012.

Butler, J.: Bodies That Matter: On the Discursive Limits of Sex, Routledge, New York, London, 1993.

Crowe, N. and Bradford, S.: "Hanging out in runescape": Identity, work and leisure in the virtual playground, Child. Geogr., 4, 331346, https://doi.org/10.1080/14733280601005740, 2006.

Demant, J. and Landolt, S.: Youth drinking in public places: The production of drinking spaces in and outside nightlife areas, Urban Stud., 51, 170-184, https://doi.org/10.1177/0042098013484532, 2014.

Douglas, M.: Constructive Drinking: Perspectives from Anthropology, Cambridge University Press, New York, 1987.

Downing, G.: Virtual youth: Non-heterosexual young people's use of the internet to negotiate their identities and socio-sexual relations, Child. Geogr., 11, 44-58, https://doi.org/10.1080/14733285.2013.743280, 2013.

Duff, C.: Accounting for context: Exploring the role of objects and spaces in the consumption of alcohol and other drugs, Soc. Cult. Geogr., 13, 145-159, https://doi.org/10.1080/14649365.2012.655765, 2012.

Fassetta, G.: Using photography in research with young migrants: Addressing questions of visibility, movement and personal spaces, Child. Geogr., 14, 701-715, https://doi.org/10.1080/14733285.2016.1190811, 2016.

Flisfeder, M.: The entrepreneurial subject and the objectivization of the self in social media, S. Atl. Quart., 114, 553-570, https://doi.org/10.1215/00382876-3130745, 2015.

Fujimoto, K. and Valente, T. W.: Decomposing the components of friendship and friends' influence on adolescent drinking and smoking, J. Adolescent Health, 51, 136-143, https://doi.org/10.1016/j.jadohealth.2011.11.013, 2012.

Furlong, A.: Youth Studies: An Introduction, Routledge, Oxon, New York, 2013.

Griffin, C., Bengry-Howell, A., Hackley, C., Mistral, W., and Szmigin, I.: "Every time I do it I absolutely annihilate my- self": Loss of (self-)consciousness and loss of memory in young people's drinking narratives, Sociology, 43, 457-476, https://doi.org/10.1177/0038038509103201, 2009.

Griffiths, R. and Casswell, S.: Intoxigenic digital spaces? Youth, social networking sites and alcohol marketing, Drug Alcohol Rev., 29, 525-530, https://doi.org/10.1111/j.1465-3362.2010.00178.x, 2010.

Hayles, N. K.: Hyper and deep attention?: The generational divide in cognitive modes, Profession, 187-99, 2007.

Jayne, M., Valentine, G., and Holloway, S. L.: Geographies of alcohol, drinking and drunkenness: A review of progress, Prog. Hum. Geog., 32, 247-263, https://doi.org/10.1177/0309132507087649, 2008.

Johnson, P.: "You just get blocked". Teenage drinkers: Reckless rebellion or responsible reproduction?, Child. Soc., 25, 394-405, https://doi.org/10.1111/j.1099-0860.2009.00288.x, 2011.

Kinsley, S.: The matter of "virtual” geographies, Prog. Hum. Geog., 38, 364-384, https://doi.org/10.1177/0309132513506270, 2014.

Langevang, T.: Movements in time and space: Using multiple methods in research with young people in Accra, Ghana, Child. Geogr., 5, 267-282, https://doi.org/10.1080/14733280701445853, 2007.

Longhurst, R.: Using Skype to mother: Bodies, emotions, visuality, and screens, Environ. Plann. D., 31, 664-679, https://doi.org/10.1068/d20111, 2013.

Longhurst, R.: Mothering, digital media and emotional geographies in Hamilton, Aotearoa New Zealand, Soc. Cult. Geogr., 17, 120 139, https://doi.org/10.1080/14649365.2015.1059477, 2016a.

Longhurst, R.: Skype: Bodies, Screens, Space, Routledge, Oxon, New York, 2016b.

Lovink, G.: Networks without a Cause: A Critique of Social Media, Polity, Malden, MA, 2011.

Lyons, A. C., Mccreanor, T., Goodwin, I., and Barnes, H. M.: Youth Drinking Cultures in a Digital World. Alcohol, Social Media and Cultures of Intoxication, Routledge, London, New York, 2017.

MacLean, S.: Alcohol and the constitution of friendship for young adults, Sociology, 50, 93-108, https://doi.org/10.1177/0038038514557913, 2016.

Malbon, B.: Clubbing: Consumption, identity and the spatial practices of every-night life, in: Cool Places: Geographies of Youth Cultures, edited by: Skelton, T. and Valentine, G., Routledge, London, 266-289, 1998.

Merleau-Ponty, M.: Phenomenology of Perception, Taylor and Francis e-Library, London, New York, 2005.

Niland, P. R., Lyons, A. C., Goodwin, I., and Hutton, F.: "Everyone can loosen up and get a bit of a buzz on": Young adults, alcohol and friendship practices, Int. J. Drug Policy, 24, 530-537, https://doi.org/10.1016/j.drugpo.2013.05.013, 2013.

Niland, P. R., Lyons, A. C., Goodwin, I., and Hutton, F.: "See it doesn't look pretty does it?" Young adults' airbrushed drinking practices on Facebook, Psychol. Health, 29, 877-895, https://doi.org/10.1080/08870446.2014.893345, 2014.

Overbeek, G., Bot, S. M., Meeus, W. H. J, Sentse, M., Knibbe, R. A., and Engels, R.: Where it's at! The role of best friends and peer group members in young adults' alcohol use, J. Res. Adolescence, 21, 631-638, https://doi.org/10.1111/j.15327795.2010.00696.x, 2011. 
Rose, G.: Cultural geography going viral, Soc. Cult. Geogr., 17, 763-767, https://doi.org/10.1080/14649365.2015.1124913, 2016a.

Rose, G.: Rethinking the geographies of cultural "objects" through digital technologies: Interface, network and friction, Prog. Hum. Geog., 40, 334-351, https://doi.org/10.1177/0309132515580493, 2016b.

Ruckenstein, M.: Spatial extensions of childhood: From toy worlds to online communities, Child. Geogr., 11, 476-489, https://doi.org/10.1080/14733285.2013.812309, 2013.

Rushkoff, D.: Present Shock: When Everything Happens Now, Penguin Group, New York, 2013.

Stiegler, B.: Taking Care of Youth and the Generations, Stanford University Press, Stanford, 2010.

Thompson, L. and Cupples, J.: Seen and not heard? Text messaging and digital sociality, Soc. Cult. Geogr., 9, 95-108, https://doi.org/10.1080/14649360701789634, 2008.

Tutenges, S.: The road of excess, Harvard Divinity Bulletin, 41, Cambridge, Mass., available at: http://bulletin.hds. harvard.edu/articles/winterspring2013/road-excess (last access: 28 May 2018), 33-40, 2013.

Tutenges, S. and Sandberg, S.: Intoxicating stories: The characteristics, contexts and implications of drinking stories among danish youth, Int. J. Drug Policy, 24, 538-544, https://doi.org/10.1016/j.drugpo.2013.03.011, 2013.

Valentine, G.: Angels and devils: Moral landscapes of childhood, Environ. Plann. D., 14, 581-599, https://doi.org/10.1068/d140581, 1996.

Valentine, G., Holloway, S. L., and Bingham, N.: Transforming cyberspace: Children's interventions in the new public sphere, in: Children's Geographies: Playing, Living, Learning, edited by: Holloway, S. L. and Valentine, G., Routledge, London, 156-173, 2000.

Valentine, G., Holloway, S. L., and Bingham, N.: The digital generation? Children, ICT and the everyday nature of social exclusion, Antipode, 34, 296-315, https://doi.org/10.1111/14678330.00239, 2002.
Valentine, G. and Skelton, T.: Changing spaces: The role of the internet in shaping deaf geographies, Soc. Cult. Geogr., 9, 469485, https://doi.org/10.1080/14649360802175691, 2008.

Wilkinson, S.: Hold the phone! Culturally credible research "with" young people, Child. Geogr., 14, 232-238, https://doi.org/10.1080/17597269.2015.1134761, 2016.

Wilkinson, S.: Drinking in the dark: Shedding light on young people's alcohol consumption experiences, Soc. Cult. Geogr., 18, 739-757, https://doi.org/10.1080/14649365.2016.1227872, 2017.

Willemse, I., Waller, G., and Süss, D.: JAMES. Jugend, Aktivitäten, Medien. Erhebung Schweiz, Zürcher Hochschule für Angewandte Wissenschaften, Zürich, 2016.

Wilton, R. and Moreno, C. M.: Critical geographies of drugs and alcohol, Soc. Cult. Geogr., 13, 99-108, https://doi.org/10.1080/14649365.2012.670505, 2012.

Winpenny, E. M., Marteau, T. M., and Nolte, E.: Exposure of children and adolescents to alcohol marketing on social media websites, Alcohol Alcoholism, 49, 154-159, https://doi.org/10.1093/alcalc/agt174, 2014.

Workman, T.: Finding the meanings of college drinking: An analysis of fraternity drinking stories, Health Commun., 13, 427-447, https://doi.org/10.1207/S15327027HC1304_05, 2001.

Y\&R Group Switzerland: Media Use Intex 2015 [Slide Presentation], Zürich, available at: http://de.slideshare.net/yr-group/ media-use-index-2015-yr-group-switzerland (last access: 28 May 2018), 2015.

Zook, M., Dodge, M., and Aoyama, Y.: New digital geographies: Information, communication, and place, in: Geography and Technology, edited by: Brunn, S. D., Cutter, S. L., and Harrington, J W., Kluwer Academic Publishers, Dordrecht, 155-176, 2004. 